\title{
American Foreign Policy Opinion in 2004: Exploring Underlying Beliefs
}

\author{
Steven E. Schier and Andrew Kaufman
}

This analysis identifies some underlying foreign policy beliefs of Americans in 2004 and explores the impact of those beliefs upon attitudes about specific foreign policies. We find, following Wittkopf $(1986,1987,1990)$, that there remains a coherence to American mass foreign policy opinion. Americans can be described as clustering into four belief sets about foreign policyaccommodationists, internationalists, isolationists and hardliners. Further, these beliefs explain variation in public responses regarding specific foreign policies, such as the proper U.S. role in world affairs, the choice of multilateral or unilateral approaches, and support of increased defense spending.

American public opinion is the subject of one of the broadest and most important research fields of political science. In the face of overwhelming evidence that Americans are often ignorant of detailed policies they are asked to offer an opinion about, can it be said that that opinion exists? If so, how can it be measured? Particularly in the field of foreign policy, where the specifics of nuclear policy, diplomacy, and other international problems are so complex that the average citizen rationally chooses not to be informed, can it be said that public opinion exists beyond what surveys and polls ask? Are the results of the questions merely a reflection of elite opinion or perhaps simply the individual's choice of party allegiance or ideological slant? Not so. In 2004, as has been shown in the past, there is a coherence to American mass foreign policy opinions, a demographically-defined typology of underlying attitudinal beliefs. That typology can be shown to be a significant predictor of policy beliefs.

This paper will begin by examining the topic's relevance in 2004. It will provide theoretical background on public opinion in general and foreign policy opinion specifically. Then, having established the past existence of a structure in American mass foreign policy opinion, we choose one method of defining that pattern (Wittkopf 1986, 1987, 1990) and attempt to replicate it, using data from 2004. This particular method is useful because the survey series used by the author has been continued. As well, imitation of a previously established methodology allows for comparison of results. Our

\footnotetext{
STEVEN E. SCHIER is Dorothy H. and Edward C. Congdon Professor of Political Science at Carleton College. ANDREW KAUFMAN is a member of the Carleton class of 2007 and winner of the Best Undergraduate Paper Award from the Presidency Research Group of the American Political Science Association.
}

The American Review of Politics, Vol. 27, Winter, 2006: 295-317

(c)2006 The American Review of Politics 
statistically significant findings suggest that, despite problems of varying question wording across time, an underlying coherence of beliefs exists in 2004 and can be compared to a similar structure in Wittkopf's previous research. The analysis will employ a typological approach to foreign policy opinion and show that that typology, based on underlying attitudinal beliefs, can be defined demographically and used to predict policy preferences. The paper will then analyze the results, comparing them to the originals from the 1980 s, discuss some of the implications for policy preferences, and conclude, relating the findings to other literature on foreign policy opinion in 2004.

Scholars reached these conclusions in the 1980s; what is the purpose of revisiting the topic in 2004? The foreign policy atmosphere of American politics has undergone drastic changes since 1984. The Cold War ended, thrusting America into a decade long (1991-2001) period where foreign policy was placed on the sidelines. President Clinton was elected and reelected on the strength of his domestic agenda and achievements; President Bush advocated a reduction of peacekeeping and nation-building policies in his successful bid for the White House. That period of tranquility ended with a shock on September 11, 2001. When the World Trade Center buildings collapsed, America was thrust into the activist-internationalist role it hadn't played since the first Gulf War. The ensuing military action in Afghanistan and Iraq served to indicate that the age of peaceful diplomacy was at an end. As evidence, foreign policy issues were front and center in the 2002 and 2004 elections, whether the question was "who can keep us safer" or "was the Iraq war the right course of action." The lull after the Cold War and the following traumatic events may have altered the structure of mass foreign policy opinion. If, for instance, the debate has been reduced to a question of partisanship, it could be said there no longer is a structure at all. Past conclusions must be revisited.

\section{Related Literature}

The nature of American public opinion regarding foreign policy can be broken down into three different issues. First, does public opinion exist at all? If it does, is polling a valid means of measurement? Second, if opinion is a valid construct, does that opinion, as it relates to foreign policy, exist in a coherent manner and does it impact electoral results? Thirdly, if the first two statements are true, then how can mass foreign policy be described and what influences it? An overview of previous research provides resolutions to the first two issues. The third is the subject of this study.

Early analyses, exemplified by Walter Lippmann, argued that Americans were fundamentally uninformed and therefore could not produce a 
coherent mass opinion (Page and Shapiro 1992, 5). Lippmann, writing of the first half of the twentieth century, postulated that 1) public opinion was likely to always be behind the course of events, and 2) that the public instinct would be to simply veto changes in policy. According importance to public opinion would handicap politicians and harm their interests (Lippman $1955,18)$. He went on to argue that "prevailing public opinion has been destructively wrong at the critical junctures" and that "[mass opinion] has shown itself to be a dangerous master of decisions when the stakes are life and death" (Lippmann 1955, 20). The crux of his argument was assigning blame to public opinion in liberal democracies for the failure of post-World War I peacemaking.

As another example, though Philip Converse allowed that a coherent structure of belief might exist for those well educated, he argued that, for the population as a whole, such a statement could not be made. He wrote that "the contextual grasp of the "standard" political belief systems fades out very rapidly, almost before one has passed beyond the 10 percent of the American population that in the 1950s had completed standard college training" (Converse 1964, 213). He showed that abstract concepts such as a liberal-conservative ideological continuum were available to only a small proportion of the population (based on open-ended interview questions). Respondents, when differing between the parties, would frequently reduce the abstract concept to a simpler reality-based division, for example a "spend-save" dichotomy. Because the mass public could not grasp the abstractions common in elite circles, they suffered "a general decline in constraint among specific belief elements that such dimensions help organize" (Converse 1964, 231). Converse also asked a series of questions to elites and the public; these questions were designed to be answered in certain patterns by an individual with a constrained belief system. The correlation among the responses was significantly higher among elites than among the masses. Finally, he showed seemingly random change in an individual's answer to similar questions over time. Converse could predict an individual's opinion at time $\mathrm{t} 3$ knowing only the value at $\mathrm{t} 1$ as well as he could knowing the value at $\mathrm{t} 2$ (Converse 1964, 242), suggesting the existence of random fluctuations in public opinion. All of this evidence led him to conclude (with supporting historical examples) that public opinion was neither coherent nor, as a result, analytically trustworthy.

George Bishop has argued that, even if public opinion exists, polls and surveys are commonly a misused tool to measure that opinion. He showed that many widely accepted conclusions regarding public opinion were affected by question wording, order, context, answer order, an absence of "DK/NO" options, and other sources of "inputted meaning" (Bishop 2005). He also outlined studies that show respondents will offer opinions on fictitious issues. 
However, two arguments support the science of public opinion polling. That public opinion was so volatile was shown to be an invalid assumption. Benjamin Page and Robert Shapiro examined thousands of Gallup Poll questions and concluded, by considering questions repeated across time, that opinion was much more likely to gradually change and very rarely fluctuated (Page and Shapiro 1992). This analysis was based on the principle that, when opinions are aggregated, the individual fluctuations represent error terms that cancel out. Bishop argues that public opinion does exist; the problem lies in its measurement. Page and Shapiro argued that public ignorance of specific political information, such as the names of public officials, does not preclude citizens from having rational, informed opinions $(1992,12)$. If the researcher takes into account the survey problems Bishop cited, valid, reliable conclusions can still be reached (Bishop 2005). Given these conclusions, we believe it is valid to focus on foreign policy opinion specifically.

Prior to the Vietnam War, a scholarly consensus existed regarding American public opinion and foreign affairs. As Walter Lippmann described it, public attitudes on foreign policy were highly volatile and "so lacking in structure and coherence that they might best be described as "non-attitudes", (Holsti 1992, 442). Those opinions, as they existed, could be described using a "single, internationalist-isolationist continuum" (Wittkopf and Maggiotto 1981, 602). Overall, "The prevailing consensus was that the public possesses very little information and only few, ill-formed attitudes about foreign affairs and is concerned deeply about these issues only when their daily lives are directly affected. As a result, such concerns are not terribly consequential in the voting booth" (Aldrich et al. 1989, 125).

More recently, scholars have revealed foreign policy attitudes to be available and accessible to the public - represented in memory and salient, as well as important influences on vote choices (Aldrich et al. 1989). Presently, there is considerable convergence on two findings regarding belief structure. "Even though the general public may be rather poorly informed, attitudes about foreign affairs are in fact structured in at least moderately coherent ways. Indeed, low information and an ambiguous foreign policy environment are actually likely to motivate rather than preclude some type of attitude structure." Further, "a single isolationist-to-internationalist dimension inadequately describes the main dimensions of public opinion on international affairs" (Holsti 1992, 448). Public opinion is not volatile to the point of being meaningless, foreign policy attitudes influence vote choice, and some sort of structure can be attributed to those attitudes, however poorly informed they may be. There are many theories regarding that structure looks like, usually different multi-dimensional outlooks (Holsti 1992, 449). One broad approach will be considered here.

Eugene Wittkopf examined polls sponsored by the Chicago Council on Foreign Relations and considered questions of that indicated underlying 
beliefs. Defined by the statements they support, he divided Americans into four attitude clusters:

Internationalists are those who support active American involvement in international affairs, favoring a combination of conciliatory and conflictual strategies. ... Isolationists, on the other hand, would oppose both types of international involvement. ... Accomodationists embrace the tenets of cooperative internationalism but reject the elements implicit in militant internationalism, while Hardliners . . . manifest just the opposite preferences (Wittkopf 1990, 25-26).

Wittkopf demonstrated that partisanship, ideology, education, and geography were important determinants for this structure in the time period he considered, 1974-86 (Wittkopf 1990, 34). He also found a "close association between Americans' foreign policy beliefs and their evaluations of policymakers' performance" (Wittkopf 1990, 106). That is, he found a relationship between underlying beliefs and policy preferences, with ideology and partisanship as additional variables in his models.

It is important to understand that analysis such as this shows that a coherent structure can be ascribed to Americans' mass foreign policy opinions, but results in merely one way to define and describe that structure. It is not valid to say the results are the structure; they are a means of definition and analysis. Another example was pioneered by Peffley and Hurwitz; they proposed a hierarchical model of public opinion (Peffley and Hurwitz 1987, 1990).

There is some argument that the structure of foreign policy opinion is more complex than Wittkopf postulates. Oldendick and Bardes $(1981,1982)$ and Bardes and Oldendick (1978) suggest that an approach utilizing more dimensions is better at describing mass beliefs. This study, however, will suggest some cross-temporal conclusions. Because question selection and wording, by necessity, vary by study, that is already a difficult task. It is best to approach the problem using fewer measures in order to minimize the differences. Then, if we find similar results, we can say that, however tentatively, such findings are unlikely to be a result of random chance. As a result, this study does not claim its results to be an ideal description of American mass foreign policy beliefs. Rather, it is evidence that such a structure exists and a suggestion of a way it can be defined.

Because the CCFR surveys continue through 2004 and a typological approach is much less statistically complex, Wittkopf's approach is used here. As Bishop and Oldendick (1978) have shown, changes in question selection and wording make it very difficult to draw conclusions across time. By replicating Wittkopf as closely as possible, we attempt to minimize those differences. His methodological approach is outlined below, along with where this study differs from it. 


\section{Methodology}

This typological analysis is based on a five part process. First, scales of attitudinal beliefs were constructed. Then, those scales were factor analyzed to establish underlying belief factors and divide the population into belief categories. To define those categories demographically, a dummy-variable based chi-squared analysis was applied with Kendall's tau-b as a measure of association. Then, logistic regression models were used to predict policy preferences only from ideology and party. The underlying belief scales were then entered to show the improvement in model performance.

Questions that are part of a group (i.e., should the President have the following powers, yes or no) can be subjected to a reliability test, as Wittkopf performed (Wittkopf 1990, 17). Cronbach's Alpha is a measure of internal consistency based on inter-item correlations. A value over .7 was considered to indicate reliability such that the questions can be converted to an overall topic score. Any item that unduly depressed the value for alpha was removed.

Those scores can be inputted into a data reduction method called factor analysis, which searches for underlying variables that explain the variance of others (Wittkopf 1990, 22-24). In this case, our selection of items was meant to as closely emulate Wittkopf's analysis as possible, given the limitations imposed by question availability. As well, it is worth pointing out that this is a very simple case of factor analysis (only four variables), making the results somewhat predictable. By constraining our analysis in this way, we minimize the differences between our methodology and Wittkopf's, enhancing our ability to draw conclusions.

Wittkopf tested the demographic correlates of his typology using Multiple Classification Analysis between his factor scores and demographic dummies (Wittkopf 1990, 35). The method here employs dummy variables (for example, Democrat or not) in a chi-squared analysis with each category, using Kendall's tau-b to establish association. The results of this analysis will reveal the demographic traits of the belief categories.

This study uses logistic regression, as Wittkopf did, to establish predictive models of policy preferences (Wittkopf 1990, 58). He theorized that ideology and partisanship were variables that needed to be controlled in that analysis. Therefore, we ran each model twice, first using only ideology and partisanship as independent variables, and then entering the belief factors. Conclusive evidence of a coherent belief pattern was found in models that perform better with the underlying belief factors taken into account. We then considered particular models to suggest conclusions regarding the structure of American mass foreign policy opinions.

The dataset is the 2004 Chicago Council on Foreign Relations (CCFR) Survey. ${ }^{1}$ It was conducted online through Knowledge Networks. The 
pollsters used Random Digit Dialing sampling techniques on a sample frame consisting of the U.S. telephone population. It is worth noting that the survey's interview method differs greatly from past CCFR surveys and that the effect of this difference is unknown. A stratified systematic sample design was applied to draw the survey sample. Limitations included question selection (for some reason, the surveyors chose not to ask question related to the Bush administration) and sample size. The initial dataset contained 1,195 respondents; the methodology, because it required answers to each of the underlying belief questions, reduced the maximum $\mathrm{n}$ to 861 . The final poststratification weights were applied; they accounted for differences between the sample and the U.S. Census for the following variables: gender, age, race, region, and education.

\section{Reliability Analysis}

After many different questions with multiple items were considered, four belief scales were selected. Though other topics showed high alpha values, including them would have made the categorization far too specific and thus sub-divided the population too extensively for robust statistical analysis For example, questions that measured an individual's general opinion on trade would have resulted in an additional factor, doubling the number of categories. We chose our items to best replicate Wittkopf's dimensions: militant and cooperative internationalism. The goal here is to suggest that an underlying structure still exists in mass foreign policy opinion, not to define that structure in the most elaborate way. Our analysis will reveal, following Wittkopf, that "mass foreign policy attitudes are structured parsimoniously" with only two factors "necessary to capture the essential elements of Americans' attitudes toward the nation's world role" (Wittkopf 1990, 21). We justify this parsimony in our results which, as Wittkopf's findings did earlier, support his inference that "if the mass of the American people manifest structural consistency (constraint) in their foreign policy beliefs or world views, it should be possible to predict their attitudes on one issue from knowledge of their attitudes on another" (Wittkopf 1990, 15).

The selected topics resulted in four belief scores. TROOPS is a scale indicating the extent a respondent answered positively to questions of the form "Would you favor or oppose the use of U.S. troops ..." BASES measures the extent to which the individual favors U.S. military bases across the world: "Do you think the United States should or should not have long-term military bases in the following places ..." FORIEGNAID is an indicator of an individual's support for a variety of types of foreign aid. DIPLOMATIC measures whether or not the person favors having diplomatic relations even with countries antagonistic towards the U.S. The alpha levels of these four 
indicators are quite high, ranging from .784 for the troops question to .899 for the bases item. ${ }^{2}$

How can it be stated conclusively that these variables represent a different phenomenon than simple policy-oriented questions? This question can best be addressed by the literature regarding the science of polling (Bishop 2005). An assumption of this study, built from Bishop's conclusions, is that polling is a valid means of assessing public opinion, as long as the researcher considers what questions are actually measuring. We argue here that these underlying belief scales measure different qualities of an individual's opinion than simple policy questions.

To show this, the TROOPS scale is compared to the series of questions in the 2004 survey asking respondents whether they would favor or oppose certain measures to combat terrorism. Both collections of items ask the same question applied to significantly different situations. As examples, the combat terrorism topics range from using torture to extract information to helping poor countries develop their economies. Likewise, the TROOPS items range from specific situations such as "if North Korea invaded South Korea" to more general concepts such as "to ensure the oil supply" or "to install democratic government in states where dictators rule." Yet TROOPS has an alpha-value of .783 (twelve items), with no items severely depressing alpha, while combating terrorism only has a value of .603 (eleven items), with a couple of items depressing the alpha level. Why is this difference important?

Wittkopf desires an alpha equal to .7 for a belief scale to be constructed; he isn't able to achieve this in every scale. Of the scales used here, TROOPS'.783 is the lowest value for alpha. We argue that a high level can indicate either an underlying attitudinal belief or a strong policy preference, but that the variety of items in the questions selected supports an assertion that they are the former. This would be invalid if, for instance, the TROOPS questions all dealt with specific situations relevant to contemporary foreign affairs. An example would be "would you support using U.S. troops if there was a border conflict between Turkey and Kurdistan" and similar questions. In all, two facts make the methodology valid: (1) the broad scope of the items and (2) the general nature of the umbrella topics, which suggests attitudes relevant across time and situation (see Appendix A for item subjects in the reliability analysis). These conclusions apply to both the BASES and FOREIGNAID scales.

The fourth scale is DIPLOMATIC, which theoretically measures an individual's belief in diplomacy as a means of foreign policy. It merits discussion because its number of items (four) is so low; what is measured by each item is therefore more relevant. The topic addresses diplomatic relations with Cuba, Iran, North Korea, and China. Cuba is a nation with whom the U.S.'s conflict is largely ideological and economic and dates back to the 
beginnings of the Cold War. Iran is a contemporary issue; alone, that question could indicate an opinion on nuclear proliferation or relations with Islamic states.

North Korea alone could also reveal opinions towards proliferation, but also represents a conflict that dates back to the 1950s and a region where thousands of U.S. troops remain stationed. Question order, one of Bishop's concerns, is relevant here. Previously in the survey, respondents were told that "the U.S. currently has about 37,000 troops in South Korea" and asked many questions about their opinion on the status of those troops and under what situations they could be used to defend South Korea or attack North Korea. It is likely that the item also indicated feelings regarding diplomacy with nations particularly likely to be a major problem for U.S. foreign policy in the near future. China, like Cuba, represents a nation with which the U.S. has severe ideological and economic differences, but also a country which respondents felt practiced unfair trade practices with the U.S. ${ }^{3}$ Therefore, that item also indicates opinion towards diplomacy in the context of current economic disputes. Taken together, even though there are only four items, they measure a significant range of opinions regarding diplomacy and so compose a belief scale that indicates a respondent's openness to diplomacy as a means in foreign policy.

\section{Factor Analysis}

The four scales are inputted into factor analysis with Varimax rotation. Factor 1, based on the TROOPS and BASES scales, measures a respondent's support for military foreign policy. Factor 2, which utilizes the FOREIGNAID and DIPLOMATIC scales, is a score of an individual's openness towards non-military foreign policy. These two dimensions closely reflect Wittkopf's (1990). His categories result in multilateral and unilateral belief dimensions, and ours do as well. As in Wittkopf's original work, Accommodationists believe in non-military measures but not military, Internationalists support both types, Isolationists neither, and Hardliners support military but not non-military foreign policy. The divide is made at the mean of the score variable; so, for example, an internationalist is someone with an above-average (positive) score for both factors. Table 1 shows the analysis. For the sake of space, the resulting categories appear only in a later section, where they are more useful to the reader.

\section{Demographics}

Wittkopf suggested that party identification, ideology, education, occupation, income, region, gender, age, religion, and race could be significant demographic correlates to his typology. All of this information can still 
be gleaned from the 2004 survey, except for occupation, which no longer appears; it is therefore disregarded. The analysis finds that party, ideology, gender, religiosity, race, income, and education all give significant results, while region and age do not. A significant result is determined if both the chi-squared and tau-b values are significant. As well, the tau-b must be positive, because a negative association would lead to results like "Accommodationists tend to be not aged 18-29," which are less indicative than positive statements. Therefore, we can make a series of statements such as "Accommodationists tend to be Democrats." As with the categorical distribution, the chart showing the results appears in a later section.

Table 1. Factor Analysis of Foreign Policy Beliefs

\begin{tabular}{lrr}
\hline & \multicolumn{2}{c}{ Component } \\
& \multicolumn{1}{c}{2} & \multicolumn{2}{c}{2} \\
\hline Support for Use of Troops & .791 & .235 \\
Support for Foreign Bases & .827 & -.031 \\
Support for Foreign Aid & .335 & .706 \\
Support for Diplomatic Approaches & -.072 & .857 \\
Extraction Method: Principal & & \\
Component Analysis. & & \\
Rotation Method: Varimax with & & \\
Kaiser Normalization. & & \\
Source: Chicago Council on Foreign Relations Survey, 2004. & \\
\hline
\end{tabular}

\section{Logistic Regression Analysis}

Wittkopf argues that "it is reasonable to hypothesize that partisanship, ideology, and foreign policy beliefs all play a part [in policy preferences]" (Wittkopf 1990, 56). We argue that not only is that a reasonable hypothesis, but it is important we be sure that policy preferences are not simply an artifact of partisanship and ideology. He used dummy variables indicating partisanship and ideology and his factor scores indicating foreign policy beliefs to construct ordinary least squares regression models, with policy preference scores as the dependent variables. For dichotomous questions, he employed logistic regression.

Logistic regression is an appropriate method for this study because the 2004 CCFR, like most surveys, produces mostly categorical data. We attempted to analyze as much of the survey as possible, that we might fully understand the predictive abilities of this belief structure. In all, dichotomous 
answers were pulled from one hundred and fourteen questions. This number constitutes a majority of the survey. ${ }^{5}$

The models were first run with no independent variables and then with only ideology and partisanship included. They were both tri-categorized variables treated as continuous (Conservative, Middle of the Road, Liberal, and Republican, Independent, and Democrat). The criteria for significance are (1) one or both coefficients significant and (2) a reasonably high value for Nagelkerke's $\mathrm{R}^{2}$. In logistic regression, high $\mathrm{R}^{2}$ values are difficult to achieve, and so the criterion here is greater than or equal to .1. Only nine of the hundred and fourteen models both contained significant coefficients and showed significant predictive ability. While many of the other models give ideology and partisanship significant coefficients, they lack robust $R^{2}$ values.

We then repeated the hundred and fourteen regressions, adding in the two factor scores indicating underlying beliefs. ${ }^{7}$ Of the hundred and fourteen models, only seven $(6.1 \%)$ failed to provide a significant coefficient to one or both belief factors. One hundred and five $(92.1 \%)$ had one or both coefficients significant and had greater Nagelkerke $\mathrm{R}^{2}$ values than the corresponding partially constrained models. Sixty-five $(57 \%)$ not only increased the predictive power of the model, but had an $\mathrm{R}^{2}$ value greater than .1. Two models had significant coefficients, but an identical $\mathrm{R}^{2}$ value to the models utilizing only Ideology and Partisanship.

The number of models with significant coefficients resulting in higher $\mathrm{R}^{2}$ values (and the robustness of many of those values) indicates first that belief factors are better at predicting policy preferences than ideology and partisanship. Secondly, when ideology and partisanship are controlled for, belief factors are significant predictors of policy preferences. A diagnostic for multi-collinearity between the independent variables reveals no problematic tolerance statistics. ${ }^{8}$

In 2004, the American public manifested a definite coherence in their foreign policy opinions. Because this typology has demographic correlates, the underlying factors are not randomly distributed throughout the population. They can be used to predict policy preferences, supporting the argument that this is a valid means to describe that structure.

\section{Comparisons Over Time}

Comparing the categorical distribution and its demographic correlates to Wittkopf's original conclusions reveals how this categorization of American mass foreign policy opinion has changed since the 1980 s. His distribution (across four years of study) and the 2004 distribution appear as Table 2. 
Table 2. Wittkopf's Categorical Distribution and 2004 Survey Results

\begin{tabular}{ccccc}
\hline & Accommodationists & Internationalists & Hardliners & Isolationists \\
\hline 1974 & 27 & 29 & 23 & 22 \\
1978 & 26 & 29 & 22 & 22 \\
1982 & 26 & 28 & 24 & 22 \\
1986 & 24 & 28 & 24 & 24 \\
2004 & $27.6(227)$ & $30.1(285)$ & $20.9(155)$ & $21.4(203)$
\end{tabular}

Source: Adapted from Figure 2.1 (Wittkopf 1990, 26); 2004 totals from authors' analysis with number of cases per category in parenthesis.

Table 2 reveals that frequencies have only really changed in two of the categories. Fewer Americans are Hardliners, while many more are Internationalists. While conclusions are tentative, it appears that non-military foreign policy ("cooperative internationalism") has become more acceptable among those who qualify as non-Isolationists, as the commonality between Hardliners and Internationalists is a support for military foreign policy ("militant internationalism"). Perhaps an extended period bereft of major conflicts (between the end of the first Gulf war and the 9-11 attacks) ${ }^{9}$ and prosperity made Americans more receptive to non-military policy solutions. Wittkopf's fundamental conclusion, however, remains the same: the majority of Americans are not isolationist, that is, they believe in some form of active foreign policy.

Regarding demographic correlates, it is difficult to make conclusions in some cases, because the definition of the terms has changed (i.e., "liberal" may not mean the same thing now as it did in 1980). However, it is important to determine which demographic variables were significant correlates and no longer are, and those for which the opposite is true. Wittkopf's correlates appear as Figure 1, and those for 2004 appear as Figure 2.

A few conclusions can be drawn about the changes in the categories. First, it is clear that region, which was significant across years in Wittkopf's model, no longer seems to matter. Americans are less divided by where they live. Second, the nature of the partisan and ideological divide has changed. Where Wittkopf found that Democrats and liberals could define both categories supporting cooperative internationalism, this analysis finds that they only were significant in defining the Accommodationists. That is, there still exists a partisan and ideological divide, not between internationalism and isolationism, but between different types of foreign policy. Additionally, there is no longer a gap between partisanship and ideology; perhaps because of the polarizing nature of the Bush administration, liberals and Democrats now find more to agree on about foreign policy. This point is discussed 


\section{Figure 1. 1974-86 Demographic Correlates of Foreign Policy Belief Types}

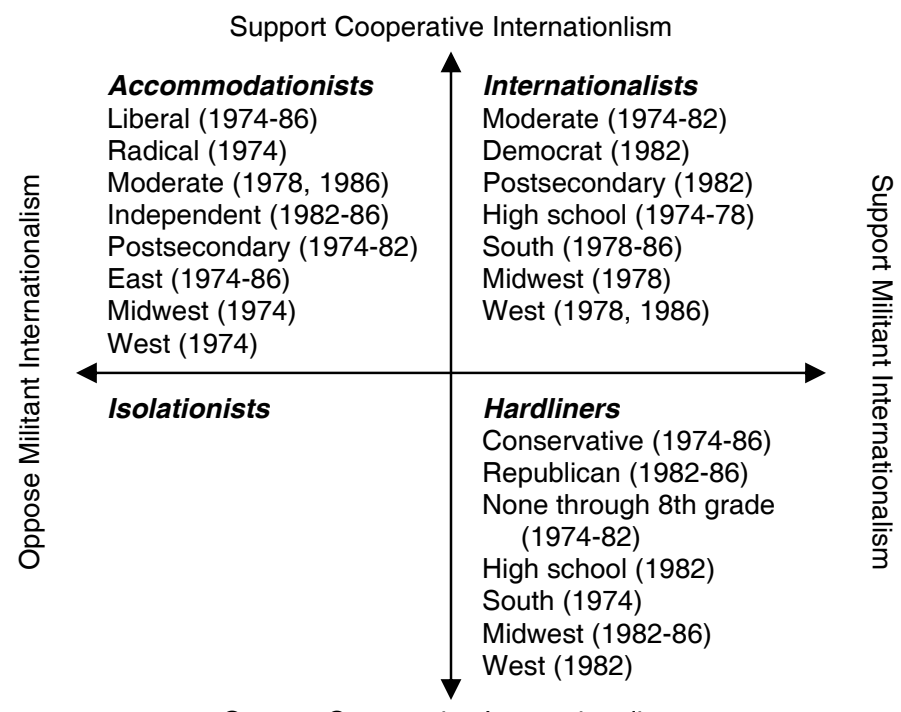

Source: Wittkopf (1990, 49), Figure 2.2.

\section{Figure 2. 2004 Correlates of Foreign Policy Belief Types}

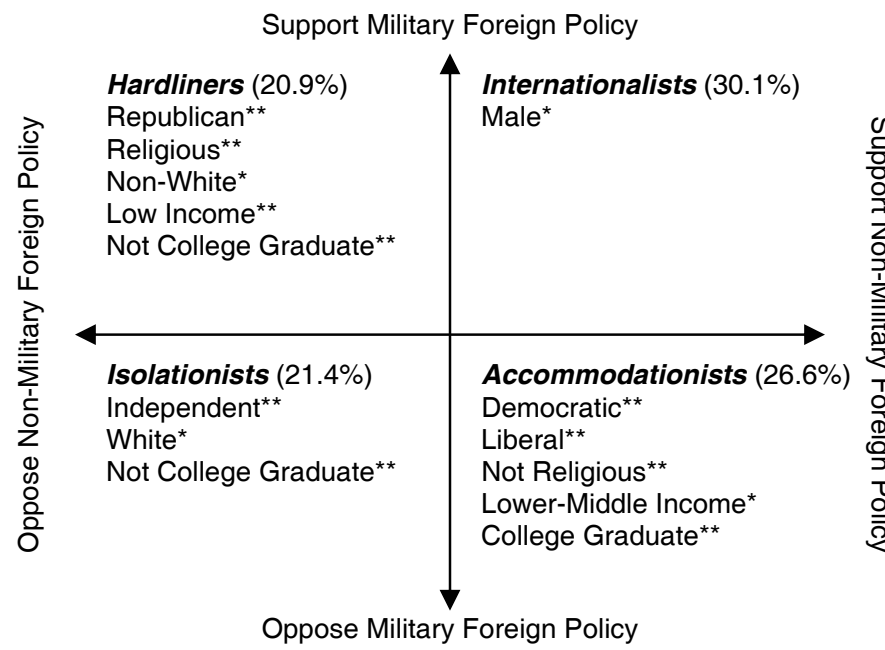

${ }^{*} \mathrm{p}<.1 ;{ }^{* *} \mathrm{p}<.05$ 
further in the conclusion. The Internationalists, previously identified by both partisan and ideological factors, now are only defined by gender. Income and gender now matter; they did not before. The only constant is that education's role seems similar - the more educated tend to support non-military foreign policy, as they supported cooperative internationalism, while the less educated oppose it. In all, significant changes to the demographic identities of the categories have occurred since the 1980s.

It is tempting to make conclusions about the category opposed to both types of foreign policy, the Isolationists. But because they represent the individuals with zero scores for all other categories (low factor scores), they can be considered an error term of sorts. That is, they correctly categorize some individuals, but also include some fundamentally not interested in foreign policy. Wittkopf reached a similar conclusion (Wittkopf 1990, 29). Therefore, assertions regarding them are somewhat questionable.

\section{Analysis of Policy Preferences}

What implications does this categorization have for Americans' specific policy preferences in 2004? While it is not possible here to analyze every regression, a discussion of three case studies serves to illustrate the impact of underlying foreign policy beliefs. ${ }^{10}$ The ensuing analysis focuses at what point on the range of the factor scores the predicted probability reaches .5 regarding a particular policy preference. This threshold demarcates where the model prediction changes from 0 to 1 .

\section{U.S. Role in World Affairs}

One of the most common questions in American foreign policy polling is "should the U.S. take an active part in world affairs or just stay out?" It has long been a measure of the public's general opinion (on the old isolationist-internationalist scale) towards America's role in the world. In the 2004 CCFR survey, 68.4 percent of those the answered the questions favored an active role. What explains this overwhelming positive response? Ideology and partisanship alone do not offer a sufficient reason. In the relevant logistic model, the coefficient for ideology was not significant $(\mathrm{p}=$ .726) and the one for partisanship is borderline significant $(p=.010)$. The partially constrained model only had an $\mathrm{R}^{2}$ value of .018 . Removing the insignificant ideology measure, consider the resulting model. Table 3 presents the variable statistics.

The percentage of cases correctly predicted rose from 68.6 to $76.3(-2$ Log likelihood went from 1064.792 to 857.015 ). As well, the Nagelkerke $\mathrm{R}^{2}$ value was .303, indicating a moderately good model fit. An examination of the predicted probability graphs (available upon request) reveals the impact 
Table 3. Variables Regressed Upon U.S. Role in World Policy Preference

\begin{tabular}{lcccccc}
\hline & B & S.E. & Wald & df & Sig. & Exp(B) \\
\hline Factor 1 & .954 & .094 & 102.950 & 1 & .000 & 2.597 \\
Factor 2 & .706 & .087 & 66.435 & 1 & .000 & 2.025 \\
Party & -.275 & .102 & 7.227 & 1 & .007 & .759 \\
Constant & 1.566 & .247 & 40.180 & 1 & .000 & 4.787 \\
$\mathrm{~N}=856$ Dependent Variable: & Should the U.S. take an active part (1) in world affairs or just say out \\
$(0) ?$ &
\end{tabular}

of underlying belief factors. Both factors lead to an increase in predicted probability, with party having very little impact. The predicted probability goes above .5 well below the mean for both factors and parties. This indicates that only a subset of those who are coded as zero for both factors would be predicted to advocate "just staying out." That definition applies to some of the Isolationists, who as a group compose only 21.4 percent of the population. Thus the underlying belief factors explain the overwhelming majority in favor of an active role.

\section{Multilateralism vs. Unilateralism}

Wittkopf has also investigated the role of multilateralist-unilateralist divide in American foreign policy opinion (Wittkopf 1986). In the aftermath of September 11th, 2001, to what extent do underlying beliefs explain it? In 2004 , over 76 percent, when given the question "What do you think is the more important lesson of September 11th; that the U.S. needs to work more closely with other countries to fight terrorism or that the U.S. needs to act on its own more to fight terrorism?", answered the former. It is reasonable to assume that, when asked the question, many respondents also considered events after 2001, because the wording did not indicate that they should try to remember their feelings at the time of the event. So it is a good barometer of Americans' feeling towards unilateralism at that point in the war on terror (2001-04). In that model, ideology and partisanship fail to be significant under the strictest standard ( $\mathrm{p}=.072$ and .015 , respectively). As well, Factor 1 is not significant $(p=.146)$. Factor 2 is the only variable left in the model. The results are as follows in Table 4.

The percentage of cases correctly predicted rose from 76.1 to $76.2(-2$ Log likelihood went from 941.198 to 852.950 ). As well, the Nagelkerke $\mathrm{R}^{2}$ value is .144, indicating a good model fit. An examination of the predicted 
Table 4. Variables Regressed Upon Multilateralism-Unilateralism Policy Preference

\begin{tabular}{lcccccc}
\hline & B & S.E. & Wald & df & Sig. & Exp(B) \\
\hline Factor 2 & .735 & .082 & 79.796 & 1 & .000 & 2.085 \\
Constant & 1.289 & .089 & 210.889 & 1 & .000 & 3.629 \\
$\begin{array}{l}\text { N = 857 Dependent Variable: What do you think is the more important lesson of September 11th, } \\
\text { that U.S. should work more closely with other countries (1), or that the U.S. should act alone (0)? }\end{array}$ \\
\hline
\end{tabular}

probability graph (available upon request) indicates that a higher Factor 2 score leads to a higher predicted probability of support for multilateralism. The value at which the predicted probability is .5 is well below the mean for the belief factor. Those who favor unilateralism are likely only to be those very opposed to non-military foreign policy, as would be extreme Hardliners and Isolationists.

\section{Defense Spending}

For the final example of the impact of underlying beliefs upon policy preferences, the question analyzed is less relevant to the long-term study of foreign policy beliefs and more relevant to the contemporary situation. Constantly an issue in presidential elections, whether the country ought to be spending more or less on defense is an issue key to defining public policy preferences. In this model, all variables were significant $(\mathrm{p}=.000, .000$, $.000)$ except for the non-military belief factor $(\mathrm{p}=.070)$, which was still borderline significant, and so all variables are included. The variable statistics compose Table 5.

The percentage of cases correctly predicted rose from 52.4 to $71.2(-2$ Log likelihood went from 661.979 to 522.505 ). As well, the Nagelkerke $\mathrm{R}^{2}$ value was .337 , indicating a reasonably good model fit. An examination of the predicted probability graphs (available upon request) shows that ideology and partisanship do have an effect on the impact of the belief factors upon policy preferences. For conservative Republicans, the probability of supporting an expansion in defense spending reaches .5 well below the mean for Factor 1. For liberal Democrats, that point is reaches well above the mean. Factor 2 has no noticeable impact, as Democrats never are predicted to support and Republicans never predicted to oppose. Therefore, ideology and partisanship are much more significant predictors of defense spending preferences than they were in other models. ${ }^{11}$ So the impact of factor scores is mixed. This makes sense because defense spending is very much a 
Table 5. Variables Regressed Upon

Defense Spending Policy Preference

\begin{tabular}{lcccccc}
\hline & B & S.E. & Wald & df & Sig. & Exp(B) \\
\hline Factor 1 & .748 & .112 & 44.635 & 1 & .000 & 2.113 \\
Factor 2 & -.190 & .105 & 3.276 & 1 & .070 & .827 \\
Party & -.589 & .138 & 18.204 & 1 & .000 & .555 \\
Ideology & -.661 & .156 & 17.952 & 1 & .000 & .516 \\
Constant & 2.751 & .383 & 51.552 & 1 & .000 & 15.652 \\
N = 479 Dependent Variable: Expand (1) or cut back (0) defense spending? & \\
\hline
\end{tabular}

partisan issue. To analyze this more complicated model, it is useful to look at a table comparing party and category (Table 6). Respondents that indicated they were Independent were removed, leaving only Democrats and Republicans.

Republicans who are Internationalists or Hardliners (high Factor 1 scores) are very likely to favor expanding defense spending, while those in the other two categories are not overwhelmingly likely to favor the opposite. Likewise, Democrats who are Internationalists or Accommodationists (high Factor 2 scores) are very likely to favor cutting defense spending, and those in the other two categories again not likely to favor expansion. These conclusions reveal why the overall opinion is mixed (52.4\% favor expansion). 57.7 percent of the population falls into one of the categories for which "very likely" probabilities can be attributed.

\section{What is Missing?}

This analysis has not accounted for all of the population. 861 individuals were given factor scores (meaning they provided answers to the relevant items). What of those 334 not included? It seems likely that analysis of mass foreign policy opinion only applies to a certain "elite" subgroup of the population. That characterization is supported by this analysis. Consider Tables 7 and 8 .

The significance of the chi-squared and gamma values (and the negative sign on the gamma values) indicates that those not included in the belief factor analysis were significantly more likely to be less interested in news about foreign affairs and be less educated than those who were included. It seems reasonable to conclude that this pattern can only be ascribed to a certain segment of society, educated and interested in foreign affairs. 
312 | Steven E. Schier and Andrew Kaufman

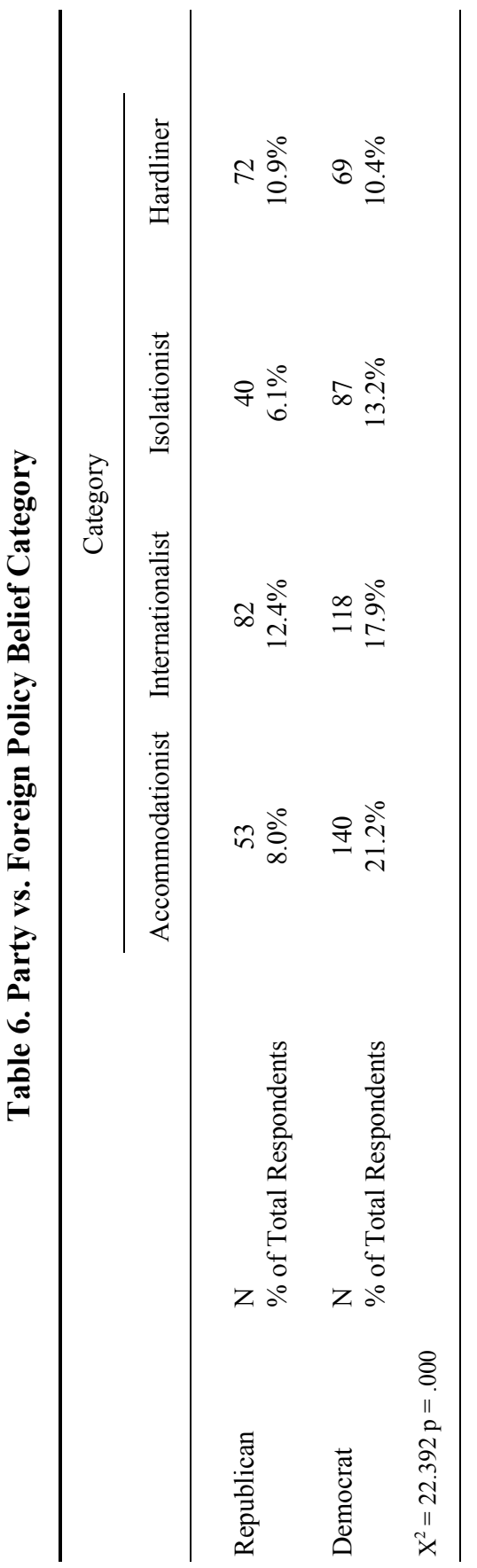




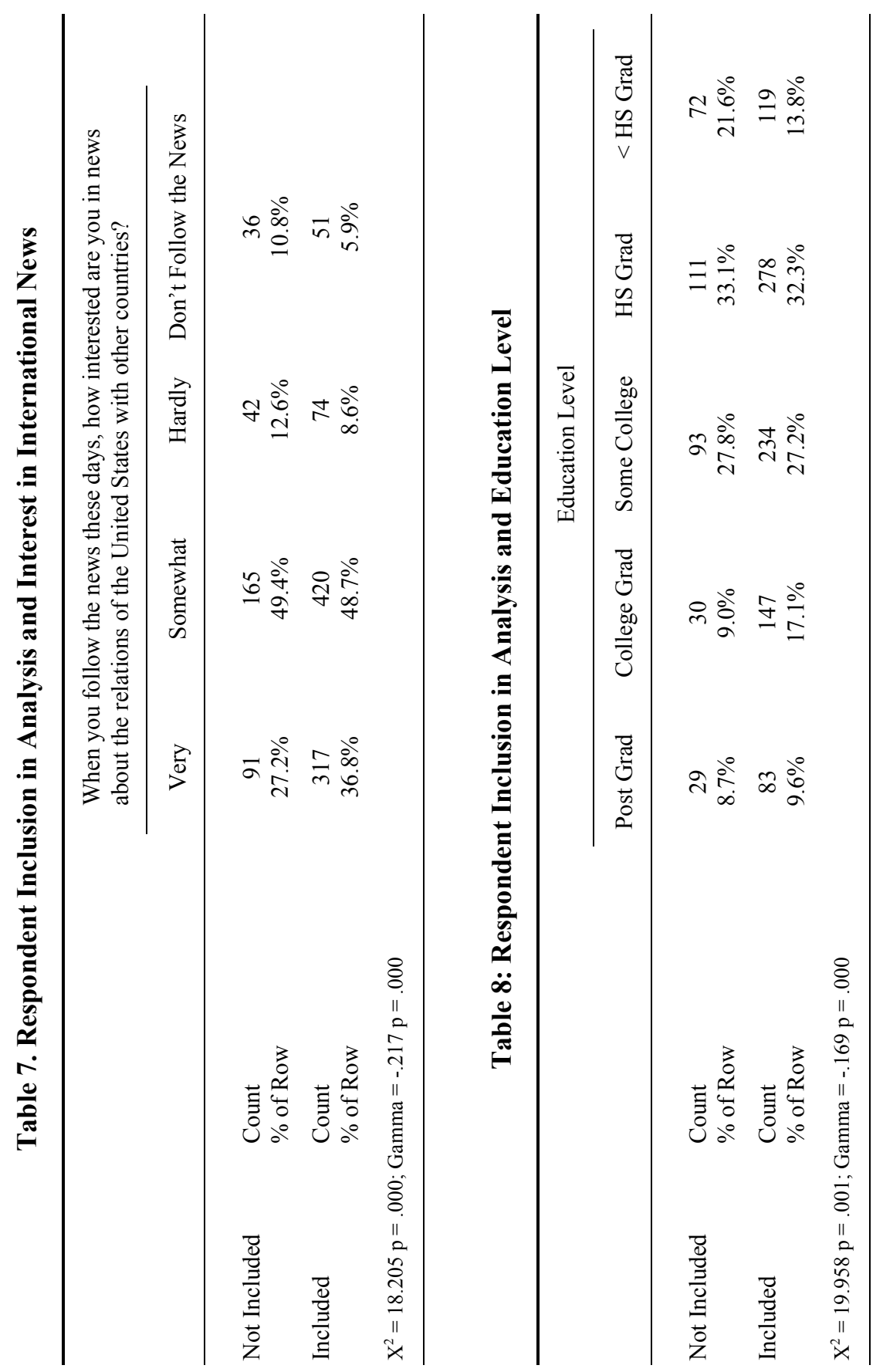




\section{Conclusion}

How can we define American foreign policy opinion in 2004? One way to define it is a typological approach that identifies underlying attitudinal beliefs, finds their demographic correlates, and shows their capabilities to predict policy preferences. This approach provides some explanation for previous research. Page and Shapiro's (1992) findings indicating stability in public opinion would be questionable if it could not be shown that some coherence pertains to it. We argue that underlying beliefs are fundamentally stable, as they are less likely than policy preferences to be affected by a given election cycle or event. Furthermore, broad issues such as whether use of the military is a valid means of foreign policy maintain relevance over a long period of time; policy issues come and go.

Comparative conclusions relating to individual demographic indicators are difficult to draw because the definition of terms changes over time. However, this paper does identify changes to the categories of demography matter in foreign policy opinion. Region no longer seems to matter, while the nature of the partisan and ideological divide has changed, centering on what means America should use in its foreign policy. Gender and income have gained in significance, while education continues to play its 1980s-era role.

We acknowledge that it is difficult to compare the category frequencies in this analysis with the ones from Wittkopf's original work, because different questions were used to compose the belief scales. However, his central conclusion is confirmed: an overwhelming majority of Americans support some type of active foreign policy. Our statistical analysis yields categorically similar results to that of Wittkopf. One might argue that we and Wittkopf have arbitrarily simplified foreign policy beliefs for the purposes of quantitative analysis. But the strong and consistent statistical significance in our data analysis argues against random error lying behind our findings and for the empirical utility of the explanatory categories discovered by Wittkopf then and by our analysis now.

The analysis reveals that underlying belief factors significantly improve the predictive capability of logistic models. The in-depth exploration of a few of those models show that ideology and partisanship still matter, particularly on questions immediately relating to partisan issues, such as defense spending. However, belief factors still make for better predictions on those issues, while for more long-running debates, such as the U.S. role in the world and the question of multi vs. unilateralism, belief factors play an even greater role. This finding is best supported by the large percentage of logistic models which showed improved predictive ability once belief factors were incorporated. 
The finding that partisanship and ideology play a greater role on issues more relating to contemporary foreign policy is unsurprising, considering some recent research. Shapiro and Bloch-Elkon, using surveys from the same CCFR series, found that, from 1998 to 2004, the mass public has become more polarized along partisan lines on issues "specific to the current situation facing the United States in the post Cold War and post September 11th world" (Shapiro and Bloch-Elkon 2005, 40). They theorize that this finding may be a temporary phenomenon associated with the Bush administration. The comparison in this study between current policy questions and questions regarding "active role" and multilateralism supports their conclusion. The evidence suggests that opinion on general goals of foreign policy remains more constant (more influenced by underlying belief factors) than more situation-specific opinions, which, while still impacted by underlying beliefs, remain subject to partisan and ideological leanings. Additionally, this study's finding that corresponding ideology and partisanship no longer define different foreign policy categories supports Shapiro and BlockElkon's conclusions.

Wittkopf concluded that while partisanship and ideology mattered, the "comparatively greater explanatory power of Americans' foreign policy beliefs deserves emphasis" (Wittkopf 1990, 105). This continues to be true in 2004. The topic merits further research, particularly that which delves more into what types of questions are best predicted by underlying beliefs, and which still require partisanship and ideology to account for their variation. The examples here have suggested a framework, but it would be worthwhile to divide questions into long-running beliefs (such as the role the U.S. should play), situation-specific questions, and opinions towards certain political figures and institutions. Even without that full analysis, this work is still suggestive of the nature of the continuing structure of American mass foreign policy opinion.

American mass foreign policy opinion is still definable by the typological methods similar to those employed by Wittkopf twenty-five years ago. The distribution and demographic characteristics attached to these beliefs, however, have changed significantly since the 1980s. The most important finding is the polarizing nature of partisanship and ideology. Additionally, the three logistic model case studies chosen for examination suggest that, as shown by Shapiro and Bloch-Elkon, partisanship remains a significant predictor for contemporary policy preferences; however, partisanship and ideology lose some of their impact when the issue is changed to long-term, broader topics. Also, this analysis concluded that this kind of large "n" statistical look at foreign policy opinion is only applicable to an elite subgroup of the population, one better educated and more interested in foreign affairs than others. 
Our results suggest that mass foreign policy opinion is not merely a random scattering of uninformed opinion. It can be used as a starting point for research into foreign policy, with mass public opinion as a predictor. Furthermore, candidates in elections may not just assume that partisanship has decided the impact of foreign policy upon their campaign; the population is more than just its partisan and ideological makeup. Most importantly, in the new century, Americans continue to present rational opinions without being entirely informed on the details of certain issues.

\section{NOTES}

${ }^{1}$ Global Views 2004: American Public Opinion and Foreign Policy, Chicago Council on Foreign Relations - ICPSR 04137.

${ }^{2}$ The full reliability analysis, including the alpha if an item were to be removed, is available from the authors upon request.

${ }^{3}$ In general, do you think the following countries practice fair trade or unfair trade with the United States? China: Fair: 39\% Unfair: 61\% (valid percent, $n=1037$ ).

${ }^{4}$ The full data analysis of the correlation of respondent demographics to their underlying beliefs is available from the authors upon request.

${ }^{5} \mathrm{We}$ omitted questions for one of three reasons. First, the questions used to construct the belief factors were not used. Secondly, some questions did not lend themselves to a dichotomy-based analysis, which is required for logistic regression. Many were tricategorized, with no one answer an obvious middle that could be disregarded. Some were coded from one to ten, and so would be better suited for OLS regression. Finally, a series of questions addressing whom the U.S. would need to work with to defend South Korea militarily was disregarded, because the repetitious nature of the items. We defend these omissions by arguing first that ignoring one answer of a clearly trichomotous question misses a significant portion of the information presented by the item. Secondly, despite omitting these questions, we are still looking a large majority of the survey. We are not making this choice based on subject matter or any reason related to the substantive content of the survey and so, our fundamental conclusion (that these belief factors can predict policy preferences) would be unlikely to change if we included these questions. Furthermore, a large proportion of the items we did consider (over 90\%) affirm our hypothesis. Even if every item we omitted did not correlate with the belief factors, the conclusion would remain the same.

${ }^{6} \mathrm{~A}$ complete set of findings of the 114 regressions is available from the authors upon request.

${ }^{7} \mathrm{~A}$ complete set of regression findings is available from the authors upon request.

${ }^{8}$ The tolerance statistics for the variables in the equation: Factor 1.923 , Factor 2 .942 , Ideology .840 , Party .818 .

${ }^{9}$ Even the conflict in the former Yugoslavia can be described as minor in scope in comparison to the post-9/11 engagements.

${ }^{10}$ The complete regression results and the descriptive statistics for the four potential independent variables are available from the authors upon request.

${ }^{11}$ In other language, partisanship and ideology are so predictive that they reduce the impact of Factor 1 and negate that of Factor 2. 


\section{REFERENCES}

Aldrich, John, John Sullivan, and Eugene Borgida. 1989. Foreign Affairs and Issue Voting: Do Presidential Candidates "Waltz Before A Blind Audience?" The American Political Science Review 83:123-141.

Bardes, Barbara Ann, and Robert Oldendick. 1978. Beyond Internationalism: A Case for Multiple Dimensions in the Structure of Foreign Policy Attitudes. Social Science Quarterly 59:496-508.

Bishop, George. 2005. The Illusion of Public Opinion: Fact and Artifact in American Public Opinion Polls. Lanham, MD: Rowman \& Littlefield.

Bishop, George F., and Robert W. Oldendick. 1978. Change in the Structure of American Political Attitudes: The Nagging Question of Question Wording. American Journal of Political Science 22:250-269.

Converse, Philip. 1964. The Nature of Belief Systems in Mass Publics. In Ideology and Discontent, ed. David E. Apter. London: Collier-Macmillan Limited.

Holsti, Ole. 1992. Public Opinion and Foreign Policy: Challenges to the Almond-Lippmann Consensus Mershon Series: Research Programs and Debates. International Studies Quarterly 36:439-466.

Holsti, Ole. 2004. Public Opinion and American Foreign Policy, rev. ed. Ann Arbor: University of Michigan Press.

Lippmann, Walter. 1955. Essays in the Public Philosophy. Boston: Little, Brown, and Company.

Maggiotto, Michael, and Eugene Wittkopf. 1981. American Public Attitudes toward Foreign Policy. International Studies Quarterly 25:601-631.

Oldendick, Robert W., and Bardes, Barbara Ann. 1982. Mass and Elite Foreign Policy Opinions. The Public Opinion Quarterly 46:368-382.

Oldendick, Robert W., and Bardes, Barbara Ann. 1981. Belief Structures and Foreign Policy: Comparing the Dimensions of Elite and Mass Opinions. Social Science Quarterly 61:434-441.

Page, Benjamin, and Robert Shapiro. 1992. The Rational Public: Fifty Years of Trends in Americans' Policy Preferences. Chicago: University of Chicago Press.

Peffley, Mark, and Jon Hurwitz. 1990. Public Images of the Soviet Union: The Impact on Foreign Policy Attitudes. The Journal of Politics 52:3-28.

Peffley, Mark, and Jon Hurwitz. 1987. How Are Foreign Policy Attitudes Structured? A Hierarchical Model. The American Political Science Review 81:1099-1120.

Peffley, Mark, and Jon Hurwitz. 1993. Models of Attitude Constraint in Foreign Affairs. Political Behavior 15:61-90.

Shapiro, Robert, and Yaeli Bloch-Elkon. 2005. Partisan Conflict, Public Opinion, and U.S. Foreign Policy (draft). Inequality and Social Policy Seminar, December 2, 2005.

Wittkopf, Eugene. 1986. On the Foreign Policy Beliefs of the American People: A Critique and Some Evidence. International Studies Quarterly 30:425-445.

Wittkopf, Eugene. 1987. Elites and Masses: Another Look at Attitudes toward America's World Role. International Studies Quarterly 31:131-159.

Wittkopf, Eugene. 1990. Faces of Internationalism: Public Opinion and American Foreign Policy. Durham, NC: Duke University Press.

Wittkopf, Eugene, and James McCormick, eds. 2004. The Domestic Sources of American Foreign Policy, 4th ed. New York: Rowman and Littlefield. 
